\title{
İlkokul Birinci ve İkinci Sınıf Türkçe Ders Kitaplarında Milli ve Kültürel Kavramlara Yer Verilme Durumu
}

Investigation of the National and Cultural Concepts in First and Second Grade Primary School Turkish Textbooks

Emine Gül ÖZENÇ, Dr. Öğr. Üyesi

Niğde Ömer Halisdemir Üniversitesi Eğitim Fakültesi Temel Eğitim Bölümü Sınıf Öğretmenliği ABD.

E-Mail: egmortas@hotmail.com

ORCID: 0000-0003-3161-4251

Hanife Gülhan ORHAN-KARSAK, Dr. Öğr. Üyesi

Kırklareli Üniversitesi Fen-Edebiyat Fakültesi Eğitim Bilimleri Bölümü.

E-Mail: gorhan811@gmail.com

ORCID: 0000-0001-5927-6341

ISSN: 1303-880X

e-ISSN: 2667-7504

http://ded.dem.org.tr

Geliş/Received: 01.04.2019

Kabul/Accepted: 14.05 .2019

Makale türü/Article type:

Araştırma/Research
Attf/Citation: Özenç, E.G. \& Orhan-Karsak, H.G. (2019). İlkokul birinci ve ikinci sinıf türkçe ders kitaplarında milli ve kültürel kavramlara yer verilme durumu. Değerler Ë̆itimi Dergisi, 17 (37), 349-379. DOI: 10.34234/ ded. 547761 
Öz: İlkokulda milli ve kültürel kavram ediminde Türkçe ders kitaplarındaki metinler oldukça öne çıkmaktadır. Bu kavramlara 2018 Türkçe dersi öğretim programında Milli Kültürümüz teması adı altında tavsiye edilen konu önerileri olarak yer verilmektedir. Yapılan bu araştırmanın amac1; ilkokul birinci ve ikinci sınıf düzeyinde, 2018-2019 eğitim-öğretim yılında kullanılan Türkçe ders kitaplarında milli ve kültürel kavramlara yer verilme durumunu belirlemektir. Çalışmada nitel yöntem kullanılmış olup, veriler doküman analizi ile toplanmış ve betimsel analiz tekniği ile çözümlenmiştir. Araştırma sonuçlarına göre; belli kavramların (örneğin Milli Mücadele ve Atatürk temasında Atatürk, bayrak kavramları), belli temalarda daha sık geçtiği; bazı kavramlarınsa incelenen ders kitaplarında yer verilen temalara yayıldığı, ilkokul birinci sınıf birinci dönem İlkokuma ve yazma ders kitabında diğer kitaplara göre daha sınırlı kavramların geçtiği belirlenmiş̧ir. Ayrıca her iki sınıf düzeyinde incelenen kavramların, yazım türlerine ve temalara göre çok fazla dengeli dağılmadığı sonuçlarına ulaşılmıştır. Yapılan çalışma sonucundan hareketle; İlkokul birinci ve ikinci s1nıf Türkçe ders kitaplarında milli ve kültürel kavramların dağılımın tekrardan gözden geçirilerek, metinlerde daha az yer verilen ya da hiç yer verilmeyen kavramların dengeli olarak dağıtılması, bazı kavramların bazı temalarda hiç yer almamasının önüne geçilmesi, milli ve kültürel kavramların aynı ya da farklı sınıf düzeylerinde farklı yayınevleri tarafından yayınlanmış ders kitaplarındaki durumunun incelenmesi önerilebilir.

Anahtar Kelimeler: İlkokul, Türkçe dersi öğretim programı, Milli ve kültürel kavramlar, Ders kitabı inceleme

$\&$

Abstract:The texts in Turkish textbooks are very important in terms of national and cultural concepts acquisition. These concepts are included in the 2018 Turkish course curriculum as the recommended topic proposals under the theme of National Culture. The purpose of this research is; to determine the status of national and cultural concepts in in First and Second Grade Primary School Turkish textbooks used in 2018-2019 academic year. Qualitative method was used in the study and data were collected by document analysis by descriptive analysis technique. According to the research results; certain concepts (such as Atatürk, flag concepts under the theme of National Struggle and Atatürk) are more frequent in certain themes; some of these concepts were distributed under the themes included in the textbooks examined, and compared to other books the first semester first-grade primary school textbook was found to contain more 
limited themes. In addition, it has been concluded that the concepts studied at both grade levels are not distributed evenly according to types of writing and themes. Based on the results of the study; The distribution of national and cultural concepts in the firs and second grade of Turkish Primary textbooks must be reviewed, concepts are given less or no place in textbooks should be distributed in more balanced way, preventing the exclusion of some themes in certain concepts, it may be suggested that examination of the situation of national and cultural concepts in different grade levels textbooks by different publishers.

Keywords: Primary school, Turkish curriculum, National and cultural concepts, Textbook investigation

\section{Giriş}

Bir milletin vazgeçilmez hazinesi şüphesiz ki anadili ve değerleridir. Bu bağlamda anadilinin ve değerlerinin erken yaşlardan itibaren nitelikli bir biçimde kazandırılması oldukça önemlidir. Bu nitelik anadili aracılığıyla, gerek ailede gerekse okullarımızda dinleme, konuşma, okuma, yazma, görsel okuma ve görsel sunu öğrenme alanlarındaki değerlere ilişkin etkinliklerle sağlanır. Bu bağlamda anadilimiz Türkçe'nin öğretimi, yalnızca bireyin ailesinin ve toplumunun dilini anlaması ve geliştirmesinde (Göğüş, 1993), bu amaçla öğrenme alanlarındaki kazanımların sağlanmasında değil, bireylerin birbirleriyle sıkı bir bağ kurmalarını sağlamada, böylece milletimizi ayakta tutan (Üstüner, t.y.) milli ve kültürel unsurların erken yaşlarda kazandırılmasında da önemli bir rol üstlenir.

Milli ve kültürel değerlerin kazanımının en hızlı ve en müsait olduğu çocukluk döneminde iyilik, ahlak ve faziletler yönünden gelişim, bireyin temel karakterini oluşturur (Mutluel, 2014). Bu nedenle erken yaşlarda milli ve kültürel değerlere ilişkin alınacak iyi bir eğitim öğretim, yaşamda sevgi, sayg1, doğruluk, dürüstlük, sorumluluk gibi insan ilişkilerini; vatan, millet, yurt, İstiklal Marşı, dini ve milli bayramlar sevgisini, milletin tarihi şahsiyetlerine ve eserlerine olan saygıy1; aile, gelenekler, geleneksel sporlar ve Türklük kavramlarına ilişkin benimsemeyi etkiler. Yine Mutluel'in (2014) belirttiği gibi milli ve kültürel değerleri benimsememiş çocukların oluşturacağı toplumun geleceği, endişe verici olur.

Bunun yanı sıra dil eğitimi, metin merkezli olarak gerçekleştirildiğinden Türkçe dersinde metin kullanımı çok önemlidir (Coşkun ve Taş, 2008: 59). 
Türkçe kitaplarında yer alan metinler millî kültürden beslenerek edebi bir dille oluşturulmalıdır. Öğrenciler bu metinlerden yararlanarak yaşadıkları ülkenin doğal güzelliklerini, her alandaki yaşam tarzını, sanat eserlerini, tarihi eserlerini, sosyal değerlerini, tarihî kahramanlarını, devlet büyüklerini, vatan ve bayrak sevgisini, manevi değerlerini, inanç sistemini tanır ve öğrenirler (Karadüz, 2008: 386). "Ana dili öğretimi işlevine sahip Türkçe derslerinde kullanılan temel materyal olan ders kitapları, kültür aktarımı için gerekli özelliklere sahip olmalıdır" (Güfta ve Kan, 2011: 240).

Bir ülkede okutulan ders kitapları, pekçok kavramları içerisinde barındırır. Şüphesiz, her milletin önem verdiği birtakım milli ve kültürel değerleri vardır. Bir milletin değerleri, okutulan ders kitaplarında yer alan metinlerde geçen milli ve kültürel kavramlarla öğretilebilmektedir. Bu yüzden ders kitapları içerisinde yer alan metinlerle geçen kavramlar önem arzetmektedir. Ayrıca çocukların hangi ahlakî değerlere göre yetiştirilmesi gerektiği hem ailenin hem okul eğitiminin hem de diğer toplumsal kurumların önemle üzerinde durması gereken bir husus olduğu düşünülünce (Dilmaç, 2002) okuldaki ders kitapları ayrı bir önem arzetmektedir.

Şahin, Oflaz ve İnceoğlu'nun (2010: 181) 18-35 yaş aralığında eğitim seviyesi en az lisans düzeyinde olan 120 katılımcıya yaptığı araştırmasında Millî Kültür temasının onlara çağrıştırdığı sözcükler üzerine yapmış oldukları araştırmaya göre 231 farklı kelimeye ulaşılmış ve bunlar 13 farklı üst anlam çevresinde toplanmıştır. Bu kelimelerin dağılımları; gelenek görenekler (51), ulusal kimlik (1), Türk mutfağ1 (34), tarihi önderler/Türk düşünürler (8), askeri (18), siyasi (33), sanat (32), spor (6), mekân (16), toplumsal değerlerimiz (14), kültürel etkileşimler (13), insan (4), ekonomi (3) şeklinde olmuştur. Alanyazında farklı araştırmalarda Türkçe ders kitaplarındaki değerlere ilişkin kavramların dengeli bir dağılıma sahip olmadığı (Şentürk ve Aktaş, 2015), incelenen metinlerde belirlenmiş değerlerin kavramlarına rastlanmadığı ve bazı değerlerin ise belli temalarda toplandığg (Doğan ve Gülüşen, 2011; Lüle-Mert (2013), sonuçlarını vurgulamaktadırlar. Ayrıca alanyazındaki araştırmalarda ifade edilenlere bakıldığında terimsel olarak "değer" ya da "kavram" şeklinde geçtiği de görülmüştür. 2018 Türkçe Öğretim Programı içerisinde "kök değerler” olarak adalet, dostluk, dürüstlük, öz denetim, sabır, sayg1, sevgi, sorumluluk, vatanseverlik, yardımseverlik geçmektedir ( http://mufredat.meb.gov.tr, s.4). Ancak 2018 Türkçe Öğretim Programı Tema ve Konu önerilerine bakıldığında "Milli Kültürümüz" teması içerisinde yer alan "aile, bayrak, büyüklerimiz, dinî bay- 
ramlar, gelenekler, geleneksel sporlar, insan ilişkileri, kültürel miras, mekânlar, millî bayramlar, şehirlerimiz, sıla/göç, tarihî mekânlar, tarihî şahsiyetler, tarihî eserlerimiz, Türkçe, vakıf kültürü, vatan, yurdumuz" şeklindeki 19 kavram geçmektedir ( http://mufredat.meb.gov.tr, s.16). İncelenen alan yazında da Milli Kültürümüz teması içinde tavsiye edilen 19 kavrama yönelik araştırmaya rastlanmamış ancak farklı şekillerde değer kavramına yönelik kitap incelemesi çalışmalarının olduğu görülmüştür (Açık-Önkaş, vd. 2011; Kolaç ve Karadağ 2012; Şen 2008; Belet ve Deveci 2008; Doğan ve Gülüşen 2011; Özensel 2003). Fakat yapılan araştırmalarda ve 2018 programındaki temada geçen 19 milli ve kültürel kavramlara yönelik araştırmaya rastlanmamıştır. Bu yüzden de çalışmada, bu kavramlar ele alınmıştır. Dolayısıyla 2018,1-8. sınıflar için yayımlanmış Türkçe dersi öğretim programı bağlamında, değerlerin kavramsal olarak kazanımında önemli bir dönem olan ilkokul birinci ve ikinci sınıf düzeyindeki Türkçe ders kitaplarında da milli ve kültürel kavramlara yer verilme durumunun incelenmesi, varsa eksikliklerin giderilmesi açısından ortaya konulabileceğinden önem arz etmektedir. Çalışmada, bu genel amaç doğrultusunda aşağıdaki sorulara yanıt aranacaktır:

1. İlkokul birinci sınıf birinci dönem ilkokuma ve yazma ders kitabında milli ve kültürel kavramlara yazım türüne ve temalara göre yer verilme durumu nedir?

2. İlkokul birinci sınıf ikinci dönem ilkokuma ve yazma ders kitabında milli ve kültürel kavramlara yazım türüne ve temalara göre yer verilme durumu nedir?

3. İlkokul ikinci sınıf Türkçe ders kitabında milli ve kültürel kavramlara yazım türüne ve temalara göre yer verilme durumu nedir?

\section{Yöntem}

\section{Araştırma Modeli}

Yapılan bu araştırma, nitel araştırma yöntemlerine uygun olarak hazırlanmıştır. Araştırmanın modeli doküman incelemesine uygundur. Doküman analizi, araştırılması hedeflenen olgu veya olgular hakkında bilgi içeren yazılı materyallerin analizini kapsar (Yıldırım ve Şimşek, 2011: 187). Yazılı materyaller kitaplar, dergiler, makaleler, tezler, anılar, fermanlar vb. olabilir (Sönmez ve Alacapınar, 2011). Veri kaynağı olan dokümanlar, internet ortamından Eğitim Bilişim A $\breve{g}$ 
olan EBA'dan elde edilmiştir. Çalışmada verilerin çözümlenmesinde nitel araştırma tekniklerinden betimsel analiz tekniği uygulanmıştır.

\section{Verilerin Toplanması ve Çözümlenmesi}

Çalışmada 2018-2019 eğitim-öğretim yılında Türkçe ders kitabı olarak okutulan (yayınlar içerisinden rastgele seçilen) MEB Yayınları tarafından yayımlanan 1. sınıf ilkokuma ve yazma öğretimi ders kitabı ve Koza Yayınları tarafından yayımlanan 2. sınıf Türkçe ders kitabı, 2018 yılında 1-8. sınıflar için hazırlanmış Türkçe dersi öğretim programında belirtilen milli ve kültürel kavramlara göre incelenmiştir. Bunun için 2018 Türkçe dersi öğretim programı incelenerek "Milli Kültürümüz" temasındaki 19 kavram olan "aile, bayrak, büyüklerimiz, dinî bayramlar, gelenekler, geleneksel sporlar, insan ilişkileri, kültürel miras, mekânlar, millî bayramlar, şehirlerimiz, sıla/göç, tarihî mekânlar, tarihî şahsiyetler, tarihî eserlerimiz, Türkçe, vakıf kültürü, vatan, yurdumuz" ele alınmıştır. Belirlenen milli ve kültürel kavramlara ilişkin kavramlara ilkokul 1. ve 2 . sınıf Türkçe ders kitaplarında yer verilme durumu yazım türü ve temalara göre belirli bir sisteme göre çözümlenmiştir. Daha sonra nitel veri analizlerinden betimsel analiz tekniğine uygun olarak kavramların, ders kitaplarındaki örnek kullanımları doğrudan alıntılarla betimlenmiştir. Yapılan bu işlemde kavramların doğrudan ve örtük olanları, tarama yoluyla bulunarak ele alınmıştır. İlkokul birinci sınıf birinci dönem İlkokuma ve yazma ders kitabında milli-kültürel kavramlar; 2018 Türkçe dersi öğretim programında yer alan kavramlar aile, bayrak, büyükler, dini bayramlar, gelenekler, geleneksel sporlar, insan ilişkileri, mekanlar, milli bayramlar, şehirlerimiz, tarihi şahsiyetler, tarihi eserler, Türkçe, vakıf kültürü, vatan, yurdumuz/yurt, millet, İstiklal Marşı, sıla/göç tür. Çalışmada kavramların kendi adı ile arama yapılmasının dışında ilgili kavram örtük ise ona göre de düşünülerek tekrar bakılmıştır. Örneğin; aile kavramı için aile kelimesine bakılmış ve bunun yanında da anne, baba, kardeş, ağabey, abla gibi bütün kavramlara bakılmıştır.

Araştırmanın içsel geçerliği bir programcı ve iki sınıf öğretmenliği doktora mezunu olan toplam üç akademisyenin kontrolüyle sağlanmıştır. Dişsal geçerlikte ise incelenen ders kitaplarından elde edilen veriler, doğrudan alıntılarla elde edilmiştir. Benzer veriler içerdikleri mesaj ve anlamlara göre belli temalar etrafında toplanmış, anlaşı1ır bir biçimde yorumlanmış ve betimlenmiştir (Özdemir, 2010; Tavşancıl ve Aslan, 2001). 


\section{Bulgular}

İlkokul birinci ve ikinci sınıf Türkçe ders kitabından elde edilen veriler tablo 1, tablo 2 ve tablo 3 de sunulmuştur:

Tablo 1: İlkokul Birinci Sınıf Birinci Dönem İlkokuma ve Yazma Ders Kitabında Milli ve Kültürel Kavramlara Yer Verilme Durumu

\begin{tabular}{|c|c|c|c|}
\hline $\begin{array}{l}\text { Milli-Kültürel } \\
\text { Kavramlar }\end{array}$ & $\begin{array}{l}\text { Yer Aldığı Yazım Türü } \\
\text { Frekansı }\end{array}$ & Yer Aldığı Tema Frekansı & $\begin{array}{l}\text { Toplam } \\
\text { Frekans }\end{array}$ \\
\hline $\begin{array}{l}\text { Aile(17) } \\
\text { Anne(6) }\end{array}$ & Etkinlik(6) & $\begin{array}{l}\text { 1.Tema Zaman ve Mekan(2) } \\
\text { 2.Tema Erdemler(1) } \\
\text { 3.Tema Milli Kültürümüz(2) } \\
\text { 4.Tema Sağlık ve Spor(1) }\end{array}$ & \multirow{4}{*}{17} \\
\hline \multirow[t]{2}{*}{$\operatorname{Baba}(7)$} & $\begin{array}{l}\text { Etkinlik(6) } \\
\text { Şiir(1) }\end{array}$ & $\begin{array}{l}\text { 3. Tema Milli Kültürümüz(5) } \\
\text { 4.Tema Sağlık ve Spor(2) }\end{array}$ & \\
\hline & Etkinlik(3) & $\begin{array}{l}\text { 3. Tema Milli Kültürümüz(2) } \\
\text { 4.Tema Sağlık ve Spor(1) }\end{array}$ & \\
\hline $\begin{array}{l}\mathrm{Abla}(3) \\
\text { Kardeş(1) }\end{array}$ & Şiir(1) & 4.Tema Sağlık ve Spor(1) & \\
\hline Bayrak (5) & $\begin{array}{l}\text { Etkinlik(1) } \\
\text { Şiir(4) }\end{array}$ & 3. $\operatorname{Tema}(5)$ & 5 \\
\hline \multicolumn{4}{|l|}{ Büyüklerimiz (14) } \\
\hline Nine(8) & $\begin{array}{l}\text { Etkinlik(6) } \\
\text { Şiir(2) }\end{array}$ & $\begin{array}{l}\text { 1.Tema Zaman ve Mekan(6) } \\
\text { 3. Tema Milli Kültürümüz(1) } \\
\text { 4.Tema Sağlık ve Spor(1) }\end{array}$ & \multirow{5}{*}{14} \\
\hline \multirow{3}{*}{$\begin{array}{l}\text { Teyze(2) } \\
\operatorname{Hala}(2)\end{array}$} & Etkinlik(2) & 4.Tema Sağlık ve Spor(2) & \\
\hline & Etkinlik(2) & 4.Tema Sağlık ve Spor(2) & \\
\hline & Şiir(1) & 4.Tema Sağlik ve Spor(1) & \\
\hline $\begin{array}{l}\text { Dede(1) } \\
\text { Nene (1) }\end{array}$ & Etkinlik(1) & 1.Tema Zaman ve Mekan(1) & \\
\hline Dini Bayramlar & 0 & 0 & 0 \\
\hline $\begin{array}{l}\text { Gelenekler } \\
\text { Türkü(1) }\end{array}$ & Şiir(1) & 3.Tema Milli Kültürümüz (1) & 1 \\
\hline Geleneksel Sporlar & 0 & 0 & 0 \\
\hline İnsan İlişkileri & 0 & 0 & 0 \\
\hline Mekanlar & 0 & 0 & 0 \\
\hline Milli Bayramlar & 0 & 0 & 0 \\
\hline $\begin{array}{l}\text { Şehirlerimiz } \\
\text { İstanbul (2) }\end{array}$ & Şiir(2) & 4.Tema Sağlık ve Spor(2) & 2 \\
\hline $\begin{array}{l}\text { Tarihi Şahsiyetler } \\
\text { Atatürk(1) }\end{array}$ & Etkinlik(1) & 3.Tema Milli kültürümüz(1) & 1 \\
\hline Tarihi Eserler & 0 & 0 & 0 \\
\hline Türkçe & 0 & 0 & 0 \\
\hline Vakıf Kültürü & 0 & 0 & 0 \\
\hline Vatan (3) & Şiir(3) & 4.Tema Sağlık ve Spor(3) & 3 \\
\hline Yurdumuz/Yurt & 0 & 0 & 0 \\
\hline Millet(1) & Şiir(1) & 3.Tema Milli kültürümüz(1) & 1 \\
\hline
\end{tabular}




\begin{tabular}{llll}
\hline Türk(1) & Şiir(1) & 3.Tema Milli kültürümüz(1) & 1 \\
\hline İstiklal Marş1 & 0 & 0 & 0 \\
\hline S1la/Göç & 0 & 0 & 0 \\
\hline Toplam & & & 45 \\
\hline
\end{tabular}

Tablo 1'e göre ilkokul birinci sınıf birinci dönem İlkokuma ve yazma ders kitabı incelendiğinde milli-kültürel kavramlardan yer verilen kavramlar frekans sırası ile; aile (17), Büyüklerimiz (14), bayrak (5), vatan (3), şehirlerimizden İstanbul'a (2), Tarihi şahsiyetlerden Atatürk (1), Millet (1), gelenekler den Türkü (1), Türk'tür (1). Dini bayramlara, insan ilişkilerine, mekanlara, milli bayramlara, Türkçe'ye, tarihi eserlere, vakıf kültürüne, yurt, İstiklal Marşı, sıla/ göç kavramlarına ilkokul birinci sınıf birinci dönem İlkokuma ve yazma ders kitabında yer verilmediği görülmüştür. En fazla frekansa sahip aile kavramının yazım türü olarak toplamda en çok etkinlik (14) türünde, tema olarak da en çok 3. Tema olan Milli Kültürümüz $(2+5+2=9)$ içerisindede geçtiği görülmüştür Büyüklerimiz kavramının da yine toplamda en çok etkinlik(15) türünde, tema olarak da toplamda 1.Tema Zaman ve Mekan $(6+1=7)$ içerisinde en çok geçtiği dikkat çeken bulgular arasındadır. Tablo 1'e göre İlkokul birinci sınıf birinci dönem İlkokuma ve yazma ders kitabında milli ve kültürel kavramlara toplamda 45 kez yer verildiği görülmüştür. Tabloya göre öğrenciler, İlkokuma yazma öğrenme sürecinde oldukları için ilk dönemde çok fazla alt başlıklara yer verilmediği düşünülebilir. İlkokul birinci sınıf birinci dönem İlkokuma ve yazma ders kitabında geçen milli ve kültürel kavramlara birkaç örnek verilecek olursa:

"Tekerleme tek tek

Okur onu Melek

Türlü türlü türküler

Okur onu anneler."

(İlkokul birinci sınıf birinci dönem ilkokuma yazma öğretimi ders kitabı, 3.Tema Milli Kültürümüz, R Harfi, s.101)

"EK

Nine kalk

Kekik ek.

Nane ek.

Kalk nine kalk.

Kekik ile nane ek."

(İlkokul birinci sınıf birinci dönem ilkokuma yazma öğretimi ders kitabı,

1.Tema Zaman ve Mekan, N Harfi, s.51) 
irmak atka takti.

\section{ta ni tani}

\section{Melike Atatürkü tanı.}

\section{Wietike Ataturkü tami.}

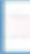

(İlkokul birinci sınıf birinci dönem ilkokuma yazma öğretimi ders kitabı, 3.Tema Milli Kültürümüz, I Harfi, s.107)

"Dim dima dim

Ellerimi yıkadım

Dedem düdük öttürdü

Ördekleri döndürdü”

(İlkokul birinci sınıf birinci dönem ilkokuma yazma öğretimi ders kitabı, 3.Tema Milli Kültürümüz, D Harfi, s.113)

\section{"BAYRAK}

Bu bayrak, al bayrak

Al bayrak benim

Türk milletinin

Daima yükselsin.”

(İlkokul birinci sınıf birinci dönem ilkokuma yazma öğretimi ders kitabı, 3.Tema Milli Kültürümüz, B Harfi, s.125) 
Tablo 2: İlkokul Birinci Sınıf İkinci Dönem İlkokuma ve Yazma Ders Kitabında Milli ve Kültürel Kavramlara Yer Verilme Durumu

\begin{tabular}{|c|c|c|c|}
\hline Milli-Külttürel Kavramlar & $\begin{array}{l}\text { Yer Aldığı Yazım Türü } \\
\text { Frekansı }\end{array}$ & $\begin{array}{l}\text { Yer Aldığı Temalara } \\
\text { Göre Frekans }\end{array}$ & $\begin{array}{l}\text { Toplam } \\
\text { Frekans }\end{array}$ \\
\hline $\begin{array}{l}\text { Aile (28) } \\
\text { Anne(17) }\end{array}$ & $\begin{array}{l}\text { Bilgilendirici(10) } \\
\text { Etkinlik(7) }\end{array}$ & $\begin{array}{l}\text { 5.Tema Çocuk Dünyası } \\
\text { (10) } \\
\text { 6.Tema Doğa ve Evren (1) } \\
\text { 7.Tema Milli Mücadele ve } \\
\text { Atatürk (2) } \\
\text { 8.Tema Bilim ve Teknoloji } \\
\text { (4) }\end{array}$ & \multirow[t]{3}{*}{28} \\
\hline Kardeş(7) & $\begin{array}{l}\text { Öyküleyici(5) } \\
\text { Etkinlik(1) } \\
\text { Şiir(1) }\end{array}$ & $\begin{array}{l}\text { 5.Tema Çocuk Dünyası (5) } \\
\text { 6.Tema Doğa ve Evren (1) } \\
\text { 7.Tema Milli Mücadele ve } \\
\text { Atatürk (1) }\end{array}$ & \\
\hline $\mathrm{Baba}(4)$ & $\begin{array}{l}\text { Bilgilendirici(3) } \\
\text { Etkinlik(1) }\end{array}$ & $\begin{array}{l}\text { 7.Tema Milli Mücadele ve } \\
\text { Atatürk(1) } \\
\text { 7.Tema Milli Mücadele ve } \\
\text { Atatürk(1) } \\
\text { 8.Tema Bilim ve } \\
\text { Teknoloji(2) }\end{array}$ & \\
\hline $\operatorname{Bayrak}(9)$ & $\begin{array}{l}\text { Bilgilendirici(3) } \\
\text { Şiir(2) } \\
\text { Etkinlik(4) }\end{array}$ & $\begin{array}{l}\text { 7.Tema Milli Mücadele ve } \\
\text { Atatürk (9) }\end{array}$ & 9 \\
\hline \multirow[t]{2}{*}{ Dede(20) } & $\begin{array}{l}\text { Bilgilendirici(12) } \\
\text { Etkinlik(7) } \\
\text { Şiir(1) }\end{array}$ & $\begin{array}{l}\text { 6.Tema Doğa ve Evren(1) } \\
\text { 7.Tema Milli Mücadele ve } \\
\text { Atatürk(12) } \\
\text { 8.Tema Bilim ve } \\
\text { Teknoloji(7) }\end{array}$ & \multirow{5}{*}{28} \\
\hline & $\begin{array}{l}\text { Etkinlik(4) } \\
\text { Şiir(2) }\end{array}$ & $\begin{array}{l}\text { 6.Tema Doğa ve Evren(4) } \\
\text { 7.Tema Milli Mücadele ve } \\
\text { Atatürk(2) }\end{array}$ & \\
\hline Nine(6) & Bilgilendirici(1) & 6.Tema Doğa ve Evren(1) & \\
\hline Annane(1) & Etkinlik(1) & 6.Tema Doğa ve Evren(1) & \\
\hline \multicolumn{3}{|l|}{ Amca(1) } & \\
\hline Dini Bayramlar & 0 & 0 & 0 \\
\hline Gelenekler & 0 & 0 & 0 \\
\hline Geleneksel Sporlar & 0 & 0 & 0 \\
\hline $\begin{array}{l}\text { İnsan İlişkileri(22) } \\
\text { (Merhamet (1), kucaklama } \\
\text { (1), ilgi (1), sorumluluk (1), } \\
\text { darılma (2), yardım etme } \\
\text { (5), kıyamama (1), kurallara } \\
\text { uyma/uygun (2), mızıç̧lık } \\
\text { (2), dışlama (1), ödünç } \\
\text { isteme (1), teşekkür etme (3), } \\
\text { arkadaş1 kutlama(1) }\end{array}$ & $\begin{array}{l}\text { Etkinlik(12) } \\
\text { Bilgilendirici(9) }\end{array}$ & $\begin{array}{l}\text { 5.Tema Çocuk Dünyası(17) } \\
\text { 6.Tema Doğa ve Evren(1) } \\
\text { 8.TemaBilim ve } \\
\text { Teknoloji(4) }\end{array}$ & 22 \\
\hline
\end{tabular}




\begin{tabular}{|c|c|c|c|}
\hline $\begin{array}{l}\text { Mekanlar(10) } \\
\operatorname{Ev}(5)\end{array}$ & $\begin{array}{l}\text { Etkinlik(2) } \\
\text { Bilgilendirici(3) }\end{array}$ & $\begin{array}{l}\text { 6.Tema Doğa ve Evren(3) } \\
\text { 7.Tema Milli Mücadele ve } \\
\text { Atatürk(1) } \\
\text { 8.Tema Bilim ve } \\
\text { Teknoloji(1) }\end{array}$ & \multirow[t]{2}{*}{10} \\
\hline Oda(5) & $\begin{array}{l}\text { Bilgilendirici(4) } \\
\text { Etkinlik(1) }\end{array}$ & 5.Tema Çocuk Dünyası(5) & \\
\hline $\begin{array}{l}\text { Milli Bayramlar } \\
23 \text { Nisan(15) }\end{array}$ & $\begin{array}{l}\text { Bilgilendirici(11) } \\
\text { Şiir(1) } \\
\text { Etkinlik(3) }\end{array}$ & $\begin{array}{l}\text { 7.Tema Milli Mücadele ve } \\
\text { Atatürk(15) }\end{array}$ & 15 \\
\hline $\begin{array}{l}\text { Şehirlerimiz(4) } \\
\text { İstanbul (2) }\end{array}$ & Etkinlik(2) & $\begin{array}{l}\text { 8.Tema Bilim ve Teknoloji } \\
(2)\end{array}$ & \multirow{3}{*}{4} \\
\hline Ankara (1) & Bilgilendirici(1) & $\begin{array}{l}\text { 7.Tema Milli Mücadele ve } \\
\text { Atatürk (1) }\end{array}$ & \\
\hline Mardin (1) & Bilgilendirici(1) & $\begin{array}{l}\text { 8.Tema Bilim ve Teknoloji } \\
\text { (1) }\end{array}$ & \\
\hline \multirow{2}{*}{$\begin{array}{l}\text { Tarihi Şahsiyetler (45) } \\
\text { Atatürk (34) }\end{array}$} & $\begin{array}{l}\text { Bilgilendirici(15) } \\
\text { Etkinlik(19) }\end{array}$ & $\begin{array}{l}\text { 7.Tema Milli Mücadele ve } \\
\text { Atatürk (34) }\end{array}$ & \multirow{4}{*}{45} \\
\hline & $\begin{array}{l}\text { Bilgilendirici(4) } \\
\text { Etkinlik(2) }\end{array}$ & $\begin{array}{l}\text { 8.Tema Bilim ve } \\
\text { Teknoloji(6) }\end{array}$ & \\
\hline Matrahçı Nasuh(3) & $\begin{array}{l}\text { Bilgilendirici(2) } \\
\text { Etkinlik(1) }\end{array}$ & $\begin{array}{l}\text { 8.Tema Bilim ve } \\
\text { Teknoloji(2) } \\
\text { 8.Tema Bilim ve } \\
\text { Teknoloji(1) }\end{array}$ & \\
\hline Hezarfen Ahmet Çelebi(2) & $\begin{array}{l}\text { Bilgilendirici(1) } \\
\text { Etkinlik(1) }\end{array}$ & $\begin{array}{l}\text { 8. Tema Bilim ve } \\
\text { Teknoloji(2) }\end{array}$ & \\
\hline $\begin{array}{l}\text { Tarihi Eserler } \\
\text { Galata Kulesi(1) }\end{array}$ & Bilgilendirici(1) & $\begin{array}{l}\text { 8. Tema Bilim ve } \\
\text { Teknoloji(1) }\end{array}$ & 1 \\
\hline Türkçe & 0 & 0 & 0 \\
\hline Vakıf Kültürü & 0 & 0 & 0 \\
\hline $\operatorname{Vatan}(15)$ & $\begin{array}{l}\text { Bilgilendirici(10) } \\
\text { Etkinlik(5) }\end{array}$ & $\begin{array}{l}\text { 7.Tema Milli Mücadele ve } \\
\text { Atatürk(15) }\end{array}$ & 15 \\
\hline Yurdumuz/Yurt(5) & $\begin{array}{l}\text { Bilgilendirici(1) } \\
\text { Etkinlik(1) } \\
\text { Şiir(3) }\end{array}$ & $\begin{array}{l}\text { 7.Tema Milli Mücadele ve } \\
\text { Atatürk(5) }\end{array}$ & 5 \\
\hline Millet(5) & $\begin{array}{l}\text { Etkinlik(1) } \\
\text { Şiir(4) }\end{array}$ & $\begin{array}{l}\text { 7.Tema Milli Mücadele ve } \\
\text { Atatürk(5) }\end{array}$ & 5 \\
\hline Türk(2) & Bilgilendirici(2) & $\begin{array}{l}\text { 8.Tema Bilim ve Tekno- } \\
\text { loji(2) }\end{array}$ & 2 \\
\hline İstiklal Marşı(6) & $\begin{array}{l}\text { Bilgilendirici(1) } \\
\text { Etkinlik(4) } \\
\text { Şiir(1) }\end{array}$ & $\begin{array}{l}\text { 7.Tema Milli Mücadele ve } \\
\text { Atatürk (6) }\end{array}$ & 6 \\
\hline Sıla/Göç & 0 & 0 & 0 \\
\hline Toplam & & & 194 \\
\hline
\end{tabular}


Tablo 2'de İnsan ilişkileri kavramı için karşılıklı iletişim ve etkileşimi ele alan merhamet, kucaklaşma, ilgi, sorumluluk... gibi (Bknz: s.20, 48, 122, 122, $47,48,22,23,16,30,126,30,34,30,34,28,97,115,30)$ kavramlar ele alınmıştır. Tablo 2' ye göre ilkokul birinci sınıf ikinci dönem İlkokuma ve yazma ders kitabı incelendiğinde milli-kültürel kavramlar olarak yer verilen kavramlar frekans sırası ile; tarihi şahsiyetler (45), aile (28) ve büyükler (28), insan ilişkileri (22), milli bayramlar (15), vatan (15), mekanlar (10), bayrak (9), istiklal marşı (6), yurt (5), millet (5), şehirlerimiz (4), Türk (2) ve tarihi eserler (1)'dir. Dini bayramlara, geleneklere, geleneksel sporlara, Türkçe'ye, vakıf kültürüne ve sıla/göç kavramlarına ilkokul birinci sınıf ikinci dönem ilkokuma ve yazma ders kitabında yer verilmediği görülmüştür. Ancak ikinci dönem ilkokuma ve yazma ders kitabında birinci dönem ders kitabına göre daha fazla kavramlara yer verildiği görülmüş ve toplamda milli ve kültürel kavramlara yer verilme durumunun 194 olduğu bulgulanmıştır. Tablo'ya göre en fazla frekansa sahip tarihi şahsiyetler (45) içerisinde alt kavram olarak Atatürk'te (34), toplamda en fazla yazım türü olarak bilgilendirici metinlerde (22) ve 7.Tema olan Milli Mücadele ve Atatürk (34) temasında en çok olduğu bulgulanmıştır. Aile (28) kavramına bakıldığında en fazla alt kavram olarak anne'nin (17) yer aldığı, toplamda aile kavramının en fazla bilgilendirici $(10+5+3=18)$ metin türünde geçtiği, yine toplamda aile kavramının en fazla ise 5 .Tema $(10+5=15)$ olan Çocuk Dünyası temasında yer aldığı bulgulanmıştır. Bunlara ek olarak en fazla yer alan diğer kavram ise büyüklerimiz (28) dir. Bunun da alt kavram olarak en çok dede (20) de geçtiği görülmüştür. Bunlara ilaveten toplamda büyüklerimiz kavramı; bilgilendirici (13) metin türünde 7.Tema olan Milli Mücadele ve Atatürk (12+2=14) temasında yer aldığı bulgulanmıştır. İlkokul birinci sınıf ikinci dönem ilkokuma ve yazma ders kitabında geçen milli ve kültürel kavramlara birkaç örnek verilecek olursa:

"Gezi alanına varınca dedem salıncağımızı kurdu." (İlkokul birinci sınıf ikinci dönem ilkokuma yazma öğretimi ders kitabı, 6.Tema Doğa ve Evren, Bir Okul Gezisi, s.74)

"-Ama gelin, dedi annem çikolatalı pasta yapacak..." (İkokul birinci sınıf ikinci dönem ilkokuma yazma öğretimi ders kitabı, 5.Tema Çocuk Dünyası, Kırmızı Balon, s.47)

“Atatürk'ün annesinin adı Zübeyde Hanım, Babasının adı Ali Rıza Efendi'ymiş." (İlkokul birinci sınıf ikinci dönem ilkokuma yazma öğretimi ders kitabı, 7. Tema Milli Mücadele ve Atatürk, Atatürk, s.88) 
“İbrahim bugün İstanbul'a gitti.” (İlkokul birinci sınıf ikinci dönem, 8. Tema Bilim ve Teknoloji, İbni Sina, s.150)

"Uçmayı başaran ilk Türk bilgini ise Hezarfen Ahmet Çelebiymiş. Galata kulesinden Üsküdar'a kadar uçmuş."

(İlkokul birinci sınıf ikinci dönem ilkokuma yazma öğretimi ders kitabı, 8 . Tema Bilim ve Teknoloji, Başıma İcat Çıkardım, s.131)

"Oyuna başlamadan kuralları öğrenirim. Oyunda mızıkçılık yaparım. Oyunu kazanan arkadaşlarımı kutlarım. Oyunun kurallarına her zaman uymam. Oyuna katılmak isteyen arkadaşlarımı dışlamam." (İlkokul birinci sınıf ikinci dönem ilkokuma yazma öğretimi ders kitabı, 5. Tema Çocuk Dünyası, Karakulak ile Tomurcuk, s.30)

“Arzu'nun mızıkçılık yapmasından hoşlanmıyorum.”(İlkokul birinci sınıf ikinci dönem ilkokuma yazma öğretimi ders kitabı, 5. Tema Çocuk Dünyası, Karakulak ile Tomurcuk, s.34)

"O benim milletimin yıldızıdır parlayacak,

O benimdir, o benim milletimindir ancak." İlkokul birinci sınıf ikinci dönem ilkokuma yazma öğretimi ders kitabı, 7. Tema Milli Mücadele ve Atatürk, 23 Nisan Kutlu Olsun, s.104) 


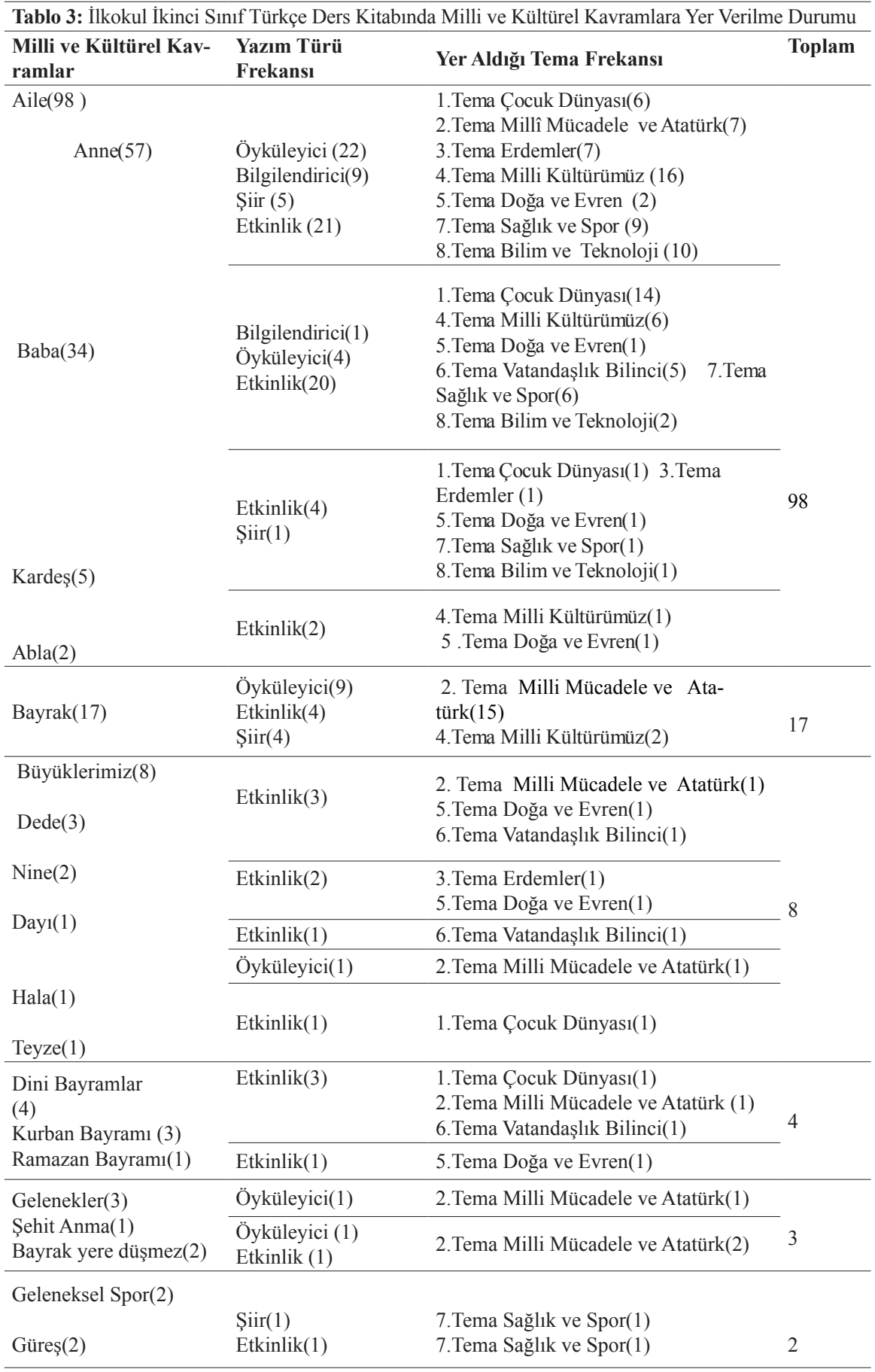




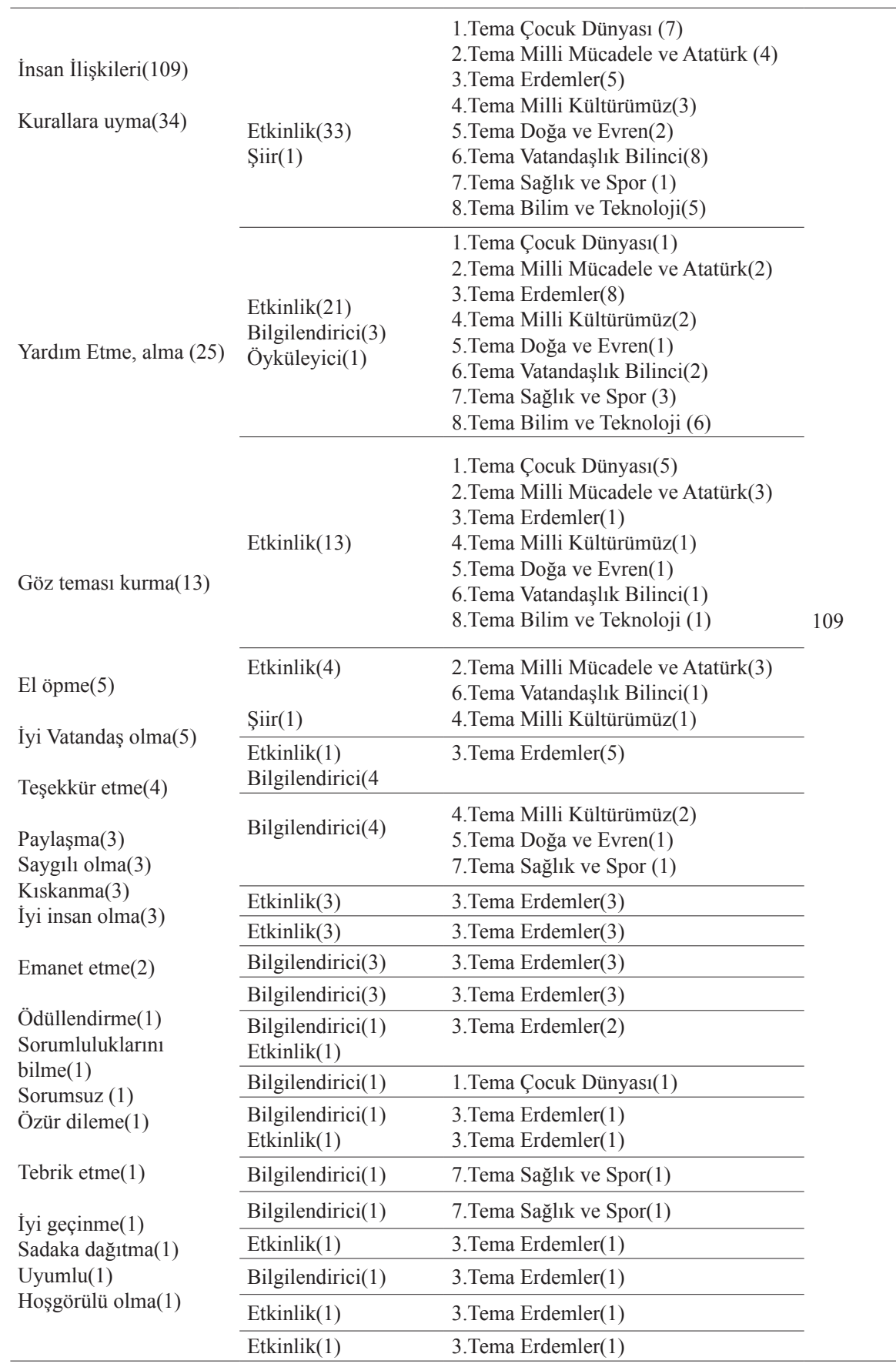




\begin{tabular}{|c|c|c|c|}
\hline Mekanlar (36) & & 1.Tema Cocuk Dünyası(3) & \\
\hline & Etkinlik(13) & 2.Tema Millî Mücadele ve Atatürk(4) & \\
\hline $\operatorname{Ev}(33)$ & Bilgilendirici(9) & 3.Tema Erdemler(9) & \\
\hline & $\operatorname{Siir}(6)$ & 5.Tema Doğa ve Evren(1) & \\
\hline & Öyküleyici(5) & 6.Tema Vatandaşlık Bilinci (7) & \\
\hline & & 7.Tema Sağlik ve Spor(3) & \\
\hline & & 8.Tema Bilim ve Teknoloji(6) & \\
\hline & Etkinlik(2) & 1.Tema Çocuk Dünyası(2) & \\
\hline $\operatorname{Park}(3)$ & Bilgilendirici(1) & 4.Tema Milli Kültürümüz(1) & \\
\hline Milli Bayramlar(3) & Etkinlik(2) & 1.Tema Çocuk Dünyası (1) & \\
\hline 23 Nisan(2) & & 3.Tema Erdemler(1) & \\
\hline 19 Mayıs(1) & Öyküleyici(1) & 2.Tema Millî Mücadele ve Atatürk(1) & 3 \\
\hline & Bilgilendirici(6) & 1.Tema Çocuk Dünyası(1) & \\
\hline Şehirlerimiz(64) & Etkinlik(6) & 4.Tema Milli Kültürümüz(10) & \\
\hline İstanbul(12) & & 6.Tema Vatandaşlık Bilinci(1) & \\
\hline & Öyküleyici(5) & 2.Tema Millî Mücadele ve Atatürk(9) & \\
\hline Çanakkale(9) & Etkinlik(4) & & \\
\hline & Etkinlik(6) & 1.Tema Çocuk Dünyası(4) & \\
\hline Ankara(7) & Öyküleyici(1) & 4.Tema Milli Kültürümüz(3) & \\
\hline & Öyküleyici(3) & 4.Tema Milli Kültürümüz(5) & \\
\hline Bursa(6) & Etkinlik(3) & 8.Tema Bilim ve Teknoloji (1) & \\
\hline & Öyküleyici(1) & & 64 \\
\hline Izmir(5) & Etkinlik(3) & 4.Tema Milli Kültürümüz(5) & \\
\hline & Bilgilendirici(1) & & \\
\hline Malatya(4) & Öyküleyici (1) & 4. Tema Milli Kültürümüz(4) & \\
\hline & Etkinlik(3) & 4. Iema Mill1 Kuiturumuz(4) & \\
\hline Şanlıurfa (4) & Etkinlik(4) & 3.Tema Erdemler(2) & \\
\hline & & 4.Tema Milli Kültürümüz(2) & \\
\hline Gaziantep(3) & Öyküleyici(1) & 1.Tema Çocuk Dünyası(1) & \\
\hline & Etkinlik(2) & 4.Tema Milli Kültürümüz(2) & \\
\hline Giresun (3) & Öyküleyici(2) & 4.Tema Milli Kültürümüz(2) & \\
\hline Samsun (2) & Etkinlik (1) & 4.Tema Milli Külttürümüz(1) & \\
\hline Santsun (2) & Öyküleyici(2) & 2.Tema Millî Mücadele ve Atatürk(9) & \\
\hline Amasya(2) & Öyküleyici(1) & 4.Tema Milli Kültürümüz(2) & \\
\hline & Etkinlik (1) & & \\
\hline Erzurum(1) & Etkinlik(1) & 4.Tema Milli Külttürümüz(1) & \\
\hline Sivas(1) & Etkinlik(1) & 5.Tema Doğa ve Evren (1) & \\
\hline $\begin{array}{l}\text { Kize(1) } \\
\text { Tekirdağ(1) }\end{array}$ & Etkinlik(1) & 4.Tema Milli Kültürümüz(1) & \\
\hline & Etkinlik (1) & 4.Tema Milli Kültürümüz(1) & \\
\hline $\begin{array}{l}\text { Adana(1) } \\
\text { Aydın(1) }\end{array}$ & Etkinlik (1) & 4.Tema Milli Kültürümüz(1) & \\
\hline Batman(1) & Etkinlik (1) & 1.Tema Çocuk Dünyası(1) & \\
\hline & Etkinlik (1) & 1.Tema Çocuk Dünyası(1) & \\
\hline
\end{tabular}




\begin{tabular}{|c|c|c|c|}
\hline $\begin{array}{l}\text { Tarihi Şahsiyetler(50) } \\
\text { Atatürk(30) }\end{array}$ & $\begin{array}{l}\text { Etkinlik(25) } \\
\text { Şiir(5) }\end{array}$ & $\begin{array}{l}\text { 1.Tema Çocuk Dünyası(1) } \\
\text { 2.Tema Milli Mücadele ve Atatürk(28) } \\
\text { 8.Tema Bilim ve Teknoloji(1) }\end{array}$ & \multirow[b]{4}{*}{50} \\
\hline $\begin{array}{l}\text { Sehit Mehmet Kâ- } \\
\text { mil(14) }\end{array}$ & $\begin{array}{l}\text { Öyküleyici(10) } \\
\text { Etkinlik(4) }\end{array}$ & 2.Tema Milli Mücadele ve Atatürk(14) & \\
\hline \multirow{2}{*}{ M. Akif Ersoy(4) } & Etkinlik(4) & 2.Tema. Milli Mücadele ve Atatürk(4) & \\
\hline & $\begin{array}{l}\text { Öyküleyici(1) } \\
\text { Etkinlik(1) }\end{array}$ & 1.Tema Çocuk Dünyası(2) & \\
\hline $\begin{array}{l}\text { Tarihi Eserler } \\
\text { Kız kulesi(12) }\end{array}$ & $\begin{array}{l}\text { Bilgilendirici (4) } \\
\text { Etkinlik(8) }\end{array}$ & 4.Tema Milli Kültürümüz(12) & 12 \\
\hline Türkçe(2) & Etkinlik(2) & $\begin{array}{l}\text { 1.Tema Çocuk Dünyası(1) } \\
\text { 2.Tema Millî Mücadele ve Atatürk (1) }\end{array}$ & 2 \\
\hline Vakıf Kültürü & 0 & 0 & 0 \\
\hline Anadolu(5) & $\begin{array}{l}\text { Öyküleyici(3) } \\
\text { Şiir(1) } \\
\text { Bilgilendirici(1) }\end{array}$ & $\begin{array}{l}\text { 2.Tema Millî Mücadele ve Atatürk(3) } \\
\text { 4.Tema Milli Kültürümüz(1) } \\
\text { 5.Tema Doğa ve Evren(1) }\end{array}$ & 5 \\
\hline Vatan(4) & $\begin{array}{l}\text { Öyküleyici (1) } \\
\text { Etkinlik(3) }\end{array}$ & $\begin{array}{l}\text { 2.Tema Milli Mücadele ve Atatürk(3) } \\
\text { 3.Tema Erdemler(1) }\end{array}$ & 4 \\
\hline Yurt(5) & $\begin{array}{l}\text { Etkinlik(1) } \\
\text { Şiir(2) } \\
\text { Bilgilendirici(2) }\end{array}$ & $\begin{array}{l}\text { 2.Tema Millî Mücadele ve Atatürk(3) } \\
\text { 4.Tema Milli Kültürümüz(2) }\end{array}$ & 5 \\
\hline Türk(8) & $\begin{array}{l}\text { Öyküleyici(2) } \\
\text { Bilgilendirici(2) } \\
\text { Etkinlik(3) } \\
\text { Şiir(1) }\end{array}$ & $\begin{array}{l}\text { 2.Tema Millî Mücadele ve Atatürk(5) } \\
\text { 4.Tema Milli Kültürümüz(3) }\end{array}$ & 8 \\
\hline İstiklal Marşı(7) & Etkinlik(7) & 2.Tema Millî Mücadele ve Atatürk(7) & 7 \\
\hline $\begin{array}{l}\text { Göç(2) } \\
\text { Sila(0) }\end{array}$ & $\begin{array}{l}\text { Bilgilendirici(1) } \\
\text { Etkinlik(1) }\end{array}$ & 6.Tema Vatandaşlık Bilinci(2) & 2 \\
\hline Toplam & & & 439 \\
\hline
\end{tabular}

Tablo 3' e göre ilkokul ikinci sınıf Türkçe ders kitabı incelendiğinde milli ve kültürel kavramlar olarak yer verilen kavramlar frekans sırası ile; İnsan ilişkileri (109), aile (98), şehirlerimiz (64), tarihi şahsiyetler (50), mekanlar (36), bayrak (17), tarihi eserler (12), büyülerimiz (8), Türk (8), İstiklal Marşı (7), Anadolu (5),yurt (5), vatan (4), dini bayramlar (4), gelenekler (3), milli bayramlar (3), geleneksel sporlar (2), Türkçe (2), göç (2)’tür.Vakıf kültürü ve sıla/göç kavramları ise İlkokul ikinci sınıf Türk ders kitabında yer verilmediği görülmüştür. Toplamda ise ilkokul Türkçe ders kitabında milli ve kültürel kavramlara yer verilme sayısı 439 olarak bulgulanmıştır. Bu bulguya göre milli ve kültürel kavramlara ilkokul birinci sınıf İlkokuma ve yazma ders kitaplarına göre ikinci sınıfta oldukça fazla yer verildiği söylenebilir. Tabloya göre en fazla frekansa sahip kavramlar insan ilişkilerinde (109) kurallara uyma (34) alt kavramındadır. En fazla frekansa sahip insan ilişkileri başlığı en çok etkinlik (93) yazma türünde ve 3.Tema olan Erdemlerde $(5+8+1+5+20=39)$ geçmektedir. İkinci yüksek frekansa sahip aile (98) kavramı da anne (57) alt başlığında toplanmıştır. Bunun 
yanında aile (98) kavramının da en yüksek etkinlik (47) türünde ve 4.Tema olan Milli Kültürümüz'de $(16+6+1=23)$ toplandığı ve bunu da 1.Tema olan Çocuk Dünyasının (21) takip ettiği görülmüştür. İlkokul ikinci Türkçe ders kitabında geçen milli ve kültürel kavramlara birkaç örnek verilecek olursa:

"Benim babam bir kaptan. Uzak ülkelere yolculuk yapar her zaman. Gittiği ülkelerden değişik armağanlar getirir bana." (İlkokul İkinci Sınıf Türkçe Ders Kitabı, 1.Tema Çocuk Dünyası, Arkadaşım Papi,s.14)

"Geçen yıl kurban bayramında köye gittik." (İlkokul İkinci Sınıf Türkçe Ders Kitabı, 2.Tema Milli Mücadele ve Atatürk, s.55)

\section{“ÜZÜM}

İzmir'de sarı üzüm

Antep’te kara üzüm.

Kurusu tazesi var,

Ye de doy iki gözüm..."

(İlkokul İkinci Sınıf Türkçe Ders Kitabı, 4.Tema Milli Kültürümüz, Üzüm, s.135)

\section{“ ÖNCE ATATÜRK}

Yurdumuzdan önce,

Bayrağımızdan önce

Atatürk’ü öğreniriz.

Acaba niye?....”

(İlkokul İkinci Sınıf Türkçe Ders Kitabı, 2.Tema Milli Mücadele ve Atatürk, Önce Atatürk, s.69)

"Nasrettin Hoca'nın yerinde siz olsaydınız hırsıza ne cevap verirdiniz?" (İlkokul İkinci Sınıf Türkçe Ders Kitabı, 1.Tema Çocuk Dünyası, s.54)

“Kız Kulesi’ni duymayanınız var mıdır bilmem. İstanbul'a gelenler görmüşlerdir." (İlkokul İkinci Sınıf Türkçe Ders Kitabı, 4.Tema Milli Kültürümüz, Kız Kulesi, s.144) 
“...Bunun yanında Ayşe, Mehmet, Türkiye, Ankara gibi isimlerin de ilk harfinin her yerde her zaman büyük yazıldığını da hatırlayacaksınız." (İlkokul İkinci Sınıf Türkçe Ders Kitabı, 1.Tema Çocuk Dünyası, s.50)

"Bu geç saatte bize yardım ettiğiniz için çok teşekkür ederiz." (İlkokul İkinci Sınıf Türkçe Ders Kitabı, 7.Tema Sağlık ve Spor, Selim ve Pelin, s.236)

“...Yurdumu nasıl savunacağım, düşmana nasıl haddini bildireceğim?...” (İlkokul İkinci Sınıf Türkçe Ders Kitabı, 2.Tema Milli Mücadele ve Atatürk, Asker Ağlamaz Arkadaş, s.88)

\section{Sonuç, Tartışma ve Öneriler}

Bu çalışmada 2018-2019 eğitim-öğretim yılında Türkçe ders kitabı olarak okutulan MEB tarafından yayımlanan 1. sınıf Türkçe ders kitabında ve Koza Yayınları tarafından yayımlanan 2. sınıf Türkçe ders kitabında, 2018 yılında 1-8. sınıflar için hazırlanmış Türkçe dersi öğretim programında belirtilen, "Milli Kültürümüz" temasındaki milli ve kültürel kavramlara ilişkin 19 kavram ele alınmıştır. Bu kavrmalar "aile, bayrak, büyüklerimiz, dinî bayramlar, gelenekler, geleneksel sporlar, insan ilişkileri, kültürel miras, mekânlar, millî bayramlar, şehirlerimiz, sıla/göç, tarihî mekânlar, tarihî şahsiyetler, tarihî eserlerimiz, Türkçe, vakıf kültürü, vatan, yurdumuz" kavramlarıdır. Yapılan inceleme sonucunda; milli ve kültürel kavramların bazılarının, İlkokul birinci ve ikinci sınıf Türkçe ders kitaplarında yeterince yer bulmadı̆̆ı, bazılarının ise hiç yer almadı $\breve{g}$ tespit edilmiştir. Bunun yanında bazı milli ve kültürel kavramlar bazı temalarda daha yoğunken bazıları da daha az yoğunluktadır.

Araştırmanın birinci alt sorusuna göre, elde edilen bulgulardan hareketle; İlkokul birinci sınıf birinci dönem İlkokuma ve yazma ders kitabında milli ve kültürel kavramlara yazım türüne ve temalara göre yer verilme durumuna bakıldığında; Aile (17) ve Büyüklerimiz (14) kavramlarının en fazla yer verilen kavramlar olduğu tespit edilmiştir. Dini bayramlara, insan ilişkileri, mekanlar, milli bayramlar, Türkçe, tarihi eserler, vakıf kültürü, yurt, İstiklal Marş1 ve sıla/ göç kavramlarına ise ilkokul birinci sınıf birinci dönem İlkokuma ve yazma ders kitabında yer verilmediği görülmüsstür. En fazla frekansa sahip aile kavramının yazım türü olarak toplamda en çok etkinlik (14) türünde, tema olarak da en çok 3. Tema olan Milli Kültürümüz (9) de geçtiği görülmüştür. Büyüklerimiz 
kavramının da yine toplamda en çok etkinlik (15) türünde, tema olarak da toplamda 1.Tema olan Zaman ve Mekan (7) içerisinde en çok geçtiği dikkat çeken bulgular arasındadır. Elde edilen sonuçlardan bir diğeri de; İlkokul birinci sınıf birinci dönem İlkokuma ve yazma ders kitabında milli ve kültürel kavramlara toplamda 45 kez yer verildiği görülmüştür.

Araştırmanın ikinci alt sorusuna bakıldığında; İlkokul birinci sınıf ikinci dönem ilkokuma ve yazma ders kitabında milli ve kültürel kavramlara yazım türüne ve temalara göre yer verilme durumuna bakıldığında; İlkokul birinci sınıf ikinci dönem İlkokuma ve yazma ders kitabı incelendiğinde milli ve kültürel kavramlar olarak yer verilen kavramlar frekans sırası olarak en çok olanlar tarihi şahsiyetler (45), aile (28) ve büyükler (28), en az olan ise tarihi eserler (1) dir. Dini bayramlara, geleneklere, geleneksel sporlara, Türkçe'ye, vakıf kültürüne ve sıla/göç kavramlarına ilkokul birinci sınıf ikinci dönem ilkokuma ve yazma ders kitabında yer verilmediği görülmüştür. Ancak ikinci dönem ilkokuma ve yazma ders kitabında birinci dönem ders kitabına göre daha fazla kavramlara yer verildiği de tespit edilmiş ve toplamda milli ve kültürel kavramlara yer verilme durumunun 194 olduğu bulgulanmıştır. En fazla frekansa sahip tarihi şahsiyetler (45) içerisinde alt kavram olarak Atatürk'te (34), toplamda en fazla yazım türü olarak bilgilendirici metinlerde (22) ve 7.Tema olan Milli Mücadele ve Atatürk (34) temasında en çok olduğu bulgulanmıştır. Aile (28) kavramına bakıldığında en fazla alt kavram olarak anne kavramının (17) yer aldığı, toplamda aile kavramının en fazla bilgilendirici (18) metin türünde geçtiği, yine toplamda aile kavramının en fazla 5.Tema (15) olan Çocuk Dünyası temasında yer aldığı bulgulanmıştır. Bunlara ek olarak en fazla yer alan diğer kavram ise büyüklerimiz (28) dir. Bunun da alt kavram olarak en çok dede (20) de geçtiği görülmüştür. Bunlara ilaveten toplamda büyüklerimiz kavram1; bilgilendirici (13) metin türünde 7.Tema olan Milli Mücadele ve Atatürk (14) temasında yer aldığ 1 ortaya çıkmıştır.

Araştırmanın üçüncü sorusuna yönelik olarak; İlkokul ikinci sınıf Türkçe ders kitabında milli ve kültürel kavramlara yazım türüne ve temalara göre yer verilme durumu; İlkokul ikinci sınıf Türkçe ders kitabı incelendiğinde milli-kültürel kavramlar olarak yer verilenler frekans sırası ile; İnsan ilişkileri (109), aile (98), şehirlerimiz (64), tarihi şahsiyetler (50), mekanlar (36), bayrak (17), tarihi eserler (12), büyülerimiz (8), Türk (8), İstiklal Marş1 (7), Anadolu (5),yurt (5), vatan (4), dini bayramlar (4), gelenekler (3), milli bayramlar (3), geleneksel sporlar (2), Türkçe (2), göç (2)’tür. Vakıf kültürü ve sıla/göç kavramlarına ise 
İlkokul ikinci sınıf Türk ders kitabında yer verilmediği görülmüştür. Toplamda ise ilkokul Türkçe ders kitabında milli ve kültürel kavramlara yer verilme sayısı 439 olarak bulgulanmıştır. Bu bulguya göre milli ve kültürel değerlere ilkokul birinci sınıf İlkokuma ve yazma ders kitaplarına göre ikinci sınıfta oldukça fazla yer verildiği söylenebilir. Tabloya göre en fazla frekansa sahip kavramlar insan ilişkilerinde (109) kurallara uyma (34) alt kavramındadır. En fazla frekansa sahip insan ilişkileri başlığ en çok etkinlik (93) yazma türünde ve 3.Tema olan Erdemlerde (39) geçmektedir. İkinci yüksek frekansa sahip aile (98) kavramı da anne (57) alt başlığında toplanmıştır. Bunun yanında aile (98) kavramının da en yüksek etkinlik (47) türünde ve 4.Tema olan Milli Kültürümüz'de (23) toplandığı ve bunu da 1.Tema olan Çocuk Dünyasının (21) takip ettiği görülmüştür.

Çalışmaya parelellik gösteren Yılar'ın (2016) Türkçe ders kitabı metinlerini incelediği çalışmasında ilkokul 3.sınıf Türkçe ders kitabında 'insan ilişkileri'ne dair kavramların en fazla yer verilen kavramlar olduğu, ders kitapları oluşturulurken, her ne kadar kimi değerler önemsenmişse de bazı değerlere ya hiç yer verilmediği bazılarına ise olması gerekenden daha az yer verildiği (Yılar, 2016:502) dile getirilmiş̧ir. Bunun yanında ders kitaplarında en çok vurgulanan değer kavramlarının sevgi, yardımseverlik, vatanseverlik, paylaşma ve saygı olduğu (Kaşkaya\& Duran, 2017), ayrıca başka araştırmalarda da kısmen benzer kavramların da olduğu (Kumbasar, 2011; Şahin, 2010) tespit edilmiştir.

Yapılan başka bir çalışmada MEB 6, 7 ve 8. sınıf Türkçe ders kitaplarında yer alan metinlerin değerlerin iletimini istenen düzeyde gerçekleştirmediği ve 6 . sınıfta değer iletiminin daha yoğun olduğu, 7 ve 8 . sınıfta ise azaldığı görülmüştür (Çelikpazu, Aktaş, 2011: 413), Doğan ve Gülüşen (2011), Kaygana, Yapıc1, Aytan (2013) Türkçe ders kitaplarındaki metinleri değer bakımından inceledikleri çalışmalarında, metinlerin değer aktarımında yeterli olmadığını tespit etmişlerdir. Kaşkaya ve Duran (2017) ders kitaplarında yer alan değerlerin büyük oranda Türkçe öğretim programında yer verilen değerlerle uyumlu olsa da sınıf düzeyindeki dağılımlarda tutarsızlıklar olduğunu, ders kitaplarında en çok geleneksel değerlere yer verildiği, en az ise bilimsel değerlere yer verildiğini, ders kitaplarında en az yer verilen değerlerin ise barış, sabır, özsaygı, merhamet, büyüklerimiz, adalet, vefa ve hoşgörü değerleri olduğunu tespit etmişlerdir. Ancak Kaşkaya ve Duran'ın (2017) sonuçların bir kısmı yapılan bu çalışma ile örtüşmemektedir. Zira büyüklerimiz kavramı ve insani ilişkilerden de bazı kavramlar frekans açısından sık geçmektedir. Yapılan diğer araştırmalarda da kısmen bu bulgu ile uyumlu ve uyumsuz sonuçların olduğu görülmüştür (Aktan \& Padem, 
2013; Aral, 2008; Çengelci, Hanc1, Karaduman, 2013; Şahin, 2010).

Firat \& Mocan'ın (2014: 25) çalışmalarında 6, 7 ve 8. Sınıf Türkçe ders kitaplarındaki hikâye metinlerinin içerdikleri değerler incelenmiş ve metinlerde altı evrensel (insan sevgisi, doğa sevgisi, sağlığa önem verme, emek, saygılı olma, barış), on altı ahlaki/manevi değer (yardımseverlik, yalan söylememe, dürüstlük), sabırlı olma, sorumluluk sahibi olma, takdir etme, çalışkanlık, vefalı olma, cömertlik, cesaret, kanaatkârlık, azimli olma, temiz olma, fedakârlık, misafirperverlik, dayanışma, dostluk) saptanmıştır. Metinlerde bir tane millî değer (ana dili sevgisi) belirlenmiştir. Görüldüğü gibi bu çalışmada da benzer milli ve kültürel kavramlar ele alınmış ve yapılan çalışma ile bazı açılardan örneğin dile ilişkin kavramlara sık rastlanmadığı açısından benzerlik taşıdığı görülmüştür.

Bütün alt soruların ortak noktalarına bakıldığında ise özetle; milli ve kültürel kavram olan "aile" kavramının her üç kitapta da ortak yüksek frekanslarda yer aldığı, vakıf kültürü ve sıla/göç kavramına her üç kitapta da yer verilmediği; ilkokul ikinci sınıf Türkçe ders kitaplarında milli ve kültürel kavramlara yer verilme durumu (439), ilkokul birinci sınıf ilkokuma ve yazma kitaplarına $(45,194)$ göre daha fazla olduğu; İlkokul birinci sınıf birinci dönem İlkokuma ve yazma ders kitabında milli ve kültürel kavramların en fazla geçtiği tema 3.Tema olan Milli Kültürümüz, İlkokul birinci sınıf ikinci dönem İlkokuma ve yazma ders kitabında milli ve kültürel kavramların en fazla geçtiği tema 7.Tema olan Milli Mücadele ve Atatürk, İlkokul ikinci sınıf ikinci Türkçe ders kitabında milli ve kültürel kavramların en fazla geçtiği tema ise yine 2. Tema olan Millî Mücadele ve Atatürk’tür.

Yapılan çalışma sonucundan hareketle; İlkokul birinci ve ikinci sınıf Türkçe ders kitaplarında milli ve kültürel kavramların dağılımın tekrardan gözden geçirilerek, metinlerde daha az yer verilen ya da hiç yer verilmeyen kavramların dengeli olarak dağıtılması, bazı kavramların bazı temalarda hiç yer almamasının önüne geçilmesi, milli ve kültürel kavramların aynı ya da farklı sınıf düzeylerinde farklı yayınevleri tarafından yayınlanmış ders kitaplarındaki durumunun incelenmesi önerilebilir.

\section{Kaynakça}

Açık-Önkaş, N., Çulha, B. Şiveroğlu, E. (2011). Türkçe ders kitaplarındaki şiirlerin fonetik-semantik ilişkisine eleştirel bir yaklaşım. 2. Uluslararası Türk Dili ve Edebiyatı Sempozyumu (Dil ve Üslûp Incelemeleri), 19-21 Ekim 2011, Isparta. 
Aktan, O., Padem, S. (2013). İlköğretim 5. sınıf sosyal bilgiler ders kitabında kullanılan okuma metinlerinde yer alan değerler. E-AJI (Asian Journal of Instruction), 1(2), 44-55

Aral, D. (2008). Millî eğitim bakanlığı’nın hazırladı̆̆ı 6. sınıf Türkçe ders kitabında yer alan değerler üzerine bir araştırma. Yayımlanmamış yüksek lisans tezi, Abant İzzet Baysal Üniversitesi, Sosyal Bilimler Enstitüsü, Bolu.

Belet, D., Deveci, H. (2008). Türkçe ders kitaplarının değerler bakımından incelenmesi. VII. ulusal sınıf ögretmenliği sempozyumu: 2-4 Mayıs - Çanakkale: Bildiriler. Çanakkale: Onsekiz Mart Üniversitesi.

Coşkun, E., Taş, S. (2008). Ders kitaplarına metin seçme açısından Türkçe öğretim programlarının değerlendirilmesi. Mustafa Kemal Üniversitesi Sosyal Bilimler Enstitüsü Dergisi, 5(10), 59-74.

Çelikpazu, E. E., Aktaş, E. (2011). MEB 6, 7 ve 8. sınıf Türkçe ders kitaplarında yer alan metinlerin değer iletimi açısından incelenmesi. Turkish Studies, 6(2), 413-424.

Çengelci, T. Hancı, B. Karaduman, H. (2013). Okul Ortamında Değerler Eğitimi Konusunda Öğretmen ve Öğrenci Görüşleri. Değerler Eğitimi Dergisi, 11(25), 33-56.

Dilmaç, B. (2002). Insanca değerler eğitimi. Ankara: Nobel Yayın Dağıtım.

Doğan, B., Gülüşen, A. (2011). Türkçe ders kitaplarındaki (6-8) metinlerin değerler bakımından incelenmesi. Sosyal Bilimler Dergisi, 1(2), 75-102.

Fırat, H., Mocan, A. (2014). Türkçe ders kitaplarındaki hikâyelerde yer alan değerler. Türkiye Sosyal Araştırmalar Dergisi, 183(183), 25-49.

Göğüş, B. (1993). Türkçe öğretimine genel bir baklş. Türkçe öğretimi ve sorunlart. Ankara: TED Yayıncılık.

Güfta, H., Kan, O. (2011). İlköğretim 7. sınıf Türkçe ders kitabının dil ile ilgili kültür ögeleri açısından incelenmesi. Mustafa Kemal Üniversitesi Sosyal Bilimler Enstitüsü Dergisi, 8(15), 239-256.

Karadüz, A. (2008). İlköğretim okulları Türkçe dersi kitaplarında millî ve kültürel değerler(s. 384-390). Türk Halkları Edebiyatı II. Çocuk Edebiyatı Kongresi, 13-15 Kasım 2008, Bakü: Azerbaycan Kafkas Üniversitesi Yayınları.

Kaşkaya, A., Duran, T. (2017). İlkokul Türkçe ders kitaplarının değer aktarımı açısından incelenmesi. Trakya Üniversitesi Eğitim Fakültesi Dergisi. 7(2), 417-441. 
Kaygana, M., Yapıcı, Ş., Aytan, T. (2013). Türkçe ders kitaplarında değer eğitimi. The Journal of Academic Social Science Studies, 6(7), 657-669.

Kolaç, E., Karadağ, R. (2012). Türkçe öğretmeni adaylarının “değer” kavramına yükledikleri anlamlar ve değer sıralamaları. İlköğretim Online, 11(3), 762-777.

Kumbasar, E. (2011). Muzaffer İzgü’nün romanlarının değerler ĕgitimi açısından incelenmesi. Yayınlanmamış yüksek lisans tezi, Karadeniz Teknik Üniversitesi Eğitim Bilimleri Enstitüsü, Trabzon.

Lüle-Mert, E. (2013). İlköğretim 6, 7 ve 8. sınıf Türkçe ders kitaplarında yer alan öykü metinlerindeki değerlerin eşdizimli sözcükler bağlamında incelenmesi. Illkögretim Online, 12(3), 808-821.

MEB (2018). Türkçe dersi ögretim programı (1-8. sınıflar). Ankara: MEB Yayınları.

Mutluel, O. (2014). Çocukta değer bilinci ve karakter eğitimi. Pamukkale Üniversitesi Illahiyat Fakültesi Dergisi, 1(2), 106-112.

Özdemir, M. (2010). Nitel veri analizi: Sosyal bilimlerde yöntembilim sorunsalı üzerine bir çalışma. Eskişehir Osmangazi Üniversitesi Sosyal Bilimler Dergisi, 1(11), 323-343.

Özensel, E. (2003). Sosyolojik bir olgu olarak değerler. Değerler Eğitimi Dergisi, 1(3).

Sönmez, V., Alacapınar, F.G. (2011). Bilimsel araştırma yöntemleri. Ankara: Anı Yayıncılık.

Şahin, A., Oflaz, E., İnceoğlu T. (2010). İlköğretim 7. ve 8. Sınıf Türkçe ders kitaplarında millî kültür temalı metinlerin ögrencilerin sözvarlı̆̆ına katkısının değerlendirilmesi. L. Subaşı uzun ve ü. Bozkurt (haz.), Türkçe ögretiminde güncel tartışmalar içinde (s. 174-185). Ankara: TÖMER Yayınları.

Şahin, K., H. (2010). İlkögrretim okullarında sosyal bilgiler dersini yürüten 4. ve 5. sinıf öğretmenlerinin sosyal bilgiler dersi ögretim programında yer alan değerlerin kazandırılmasına ilişkin görüşleri. Yayınlanmamış yüksek lisans tezi, Gazi Üniversitesi Eğitim Bilimleri Enstitüsü, Ankara.

Şen, Ü. (2008). Altıncı sınıf Türkçe ders kitaplarındaki metinlerin ilettiği değerler açısından incelenmesi. Uluslararası Sosyal Araştırmalar Dergisi, 1(5), 763779.

Şentürk, L., Aktaş, E. (2015). Türkiye'de ve Romanya'da okutulan ana dili Türkçe ders kitaplarının değer iletimi açısından karşılaştırılması. Dĕgerler Eğitimi Dergisi, 13(29), 215-243.

Tavşancıl, E., Aslan, E. (2001). İçerik analizi ve uygulama örnekleri. İstanbul: Epsilon Yayınları. 
Üstüner, A. (t.y.). Türkçe'nin Anlatım Gücü. Erişim: 2 Şubat 2019, http://www. dilimiz.com/makaleler/tranlatimgucu.htm

Yılar, R. (2016). İlettiği değerler açısından ilkokul Türkçe ders kitaplarındaki metinler üzerinde incelemeler. Journal of Bayburt Education Faculty, 11(2), 491-506

Yıldırım, A., Şimşek, H. (2011). Nitel araştırma yöntemleri. Ankara: Seçkin Yayıncilik.

http://mufredat.meb.gov.tr/dosyalar/201812312239736-t\%c3\%bcrk\%c3\%a7e\%20 \%c3\%96\%c4\%9fretim\%20program\%c4\%b1\%202018.pdf, s16. Erişim tarihi: 10 Mart 2019 


\title{
Investigation of the National and Cultural Concepts in First and Second Grade Primary School Turkish Textbooks
}

\author{
Emine Gül ÖZENÇ, Corresponding Author. Assistant Professor. \\ Niğgde Ömer Halisdemir University, Faculty of Education, Department of Basic Education, Depart- \\ ment of Classroom Teaching.
}

E-Mail: egmortas@hotmail.com

ORCID: 0000-0003-3161-4251

\section{Hanife Gülhan ORHAN-KARSAK, Assistant Professor. \\ Kırklareli University, Faculty of Science and Letters, Department of Educational Sciences. \\ E-Mail: gorhan811@gmail.com \\ ORCID: 0000-0001-5927-6341}

\section{Introduction}

Childhood is the best period to acquire national and cultural values, and the basic character of an individual is formed by the development of goodness, ethic and other virtues (Mutluel, 2014). For this reason, a good education to be taken about national and cultural values in early ages attracts adoptation of human relationships such as love, respect, truth, honesty and responsibility in life; homeland, nation, homeland, national anthem, religious and national holidays, the respect of the nation's historical personality and works; family, traditions, traditional sports, and Turkish. As stated by Mutluel (2014), the future of the society that is built by children who have not adopted national cultural values, is alarming.

In addition, the use of texts in Turkish language is very important as language education is carried out in a text-oriented manner (Coşkun and Taş, 2008: 59). The texts in the Turkish textbooks should be formed by a literary language 
loaded with national culture. Through these texts students would learn and know the natural beauty of their country, life style, art works, historical artifacts, social values, historical heroes, state elders, the love of nation and flag, spiritual values, and belief system(Karadüz, 2008: 386). Textbooks, which are the main material used in Turkish lessons with the function of teaching native language, should have the necessary features for cultural transfer ders (Güfta \& Kan, 2011: 240).

In every country, textbooks contain many concepts. Every nation has its own national and cultural values. The values of a nation can be taught by the national and cultural concepts mentioned in the textbooks. Therefore, the concepts that are included in the textbooks are important. Moreover, the fact that children should be raised according to moral values should concern his or her family the school other social institutions (Dilmaç, 2002), thus textbooks in the school are of special importance.

\section{Purpose}

In the 2018 Turkish Teaching Curriculum, justice, friendship, honesty, self-control, patience, respect, love, responsibility, patriotism, benevolence are expressed as root values (http://mufredat.meb.gov.tr, p.4). However, when looking at the 2018 Turkish Teaching Curriculum Themes and the suggested subjects, what is seen is that in the "National Culture" subject there are 19 concepts as; family, flag, elders, religious holidays, traditions, traditional sports, human relations, cultural heritage, places, national holidays, cities, reunion, historical places, historical figures, historical works, Turkish, foundation culture, homeland, our country concepts is expressed (http://mufredat.meb.gov.tr, p.16). In the literature, there is no research concerning the 19 concepts suggested in the theme of National Culture, but it has been seen that there are studies examining books about value concept in different ways (Açık-Önkaş, et al., 2011; Kolaç and Karadağ 2012; Şen 2008; Belet and Deveci 2008; Doğan and Gülüşen 2011; Özensel 2003). However, there are no studies about 19 national and cultural concepts expressed in 2018 program. Therefore, in the study, the aforementioned concepts are discussed. 2018, in the context of the Turkish course curriculum published for the 1-4 classes, it is important to examine the status of national and cultural concepts in the first and second grade Turkish textbooks, which is an important period in terms of the conceptual gain of values, as well as to reveal the deficiencies. In this study, the following questions will be addressed in terms of this general purpose: 
1. What is the place of national and cultural concepts according to the writing type and themes in the first-grade, the first term reading and writing textbook?

2. What is the place of national and cultural concepts according to the type of writing and themes in the first grade, second term reading and writing textbook?

3. What is the place of national and cultural concepts according to the type of writing and themes in the second grade, first term PrimaryTurkish textbook?

\section{Methodology}

\section{Research Model}

The research has been prepared according to qualitative research methods. The model of the study is suitable for document review. Document analysis include the phenomenon to be investigated or the analysis of the written materials containing information about that phenomenon (Yıldırım \& Şimşek, 2011: 187). Written materials could be; books, journals, articles, theses, memories, edicts and so on. (Sönmez and Alacapınar, 2011). In this study, the data source are the documents obtained from EBA, which is Education Informatics Network. In this study, descriptive analysis technique was used to analyze the data.

\section{Data Collection and Analysis}

In this study, primary school, first-grade level, first reading and writing teaching textbook published by the Ministry of Education (MEB) Publications as a Turkish textbook in 2018-2019 academic year, and the second-year class Turkish textbook published by Koza Publications will be examined according to the national and cultural concepts included in the curriculum. For this purpose, the 2018 Turkish course curriculum is examined in terms of the 19 concepts under the theme of 'our national cultural' and these concepts are: family, flag, elders, religious festivals, traditions, traditional sports, human relations, cultural heritage, places, national festivals, cities, foundation, historical places, history,, personalities, historical works, Turkish, foundation culture, homeland, our country. The concepts related to the national-cultural concepts determined in the first and second class Turkish textbooks are analyzed according to a specific system 
according to the type of writing and the themes. Then, from the qualitative data analysis, the use of concepts in the textbooks in accordance with the descriptive analysis technique was described by direct quotations. In this process, the direct and implicit ones are examined through scanning. In addition to searching the concepts by the name in the study, while considering the implicit concepts, a re-examined is done in this respect. For example; For the concept of family, it has been searched with its name and the words related to it like; mother, father, brother, brother or sister.

The internal validity of the study was ensured by the control of three academicians, with $\mathrm{PhD}$ degrees one as a programmer and two in elementary education. In terms of external validity, the data from the analyzed textbooks were obtained by direct quotations. Similar data is collected and evaluated according certain themes in terms of the messages and meanings they contain (Özdemir, 2010; Tavşanc1l \& Aslan, 2001).

\section{Findings}

As the place of National and Cultural Concepts according to writing type and themes in primary school first grade, first term reading and writing textbook are given in the order of their frequency: family (17), our elders (14), flag (5), homeland (3), from our cities to Istanbul (2), from historical figures Atatürk (1), nation (1), in traditions folk songs (1), Turk (1). Religious holidays, human relations, places, national holidays, Turkish, historical artifacts, culture of the foundation, homeland, anthem are not included in first term, first grade primary school textbook. In addition, in the first term of the first grade primary school reading and writing textbook, national and cultural concepts were 45 in total.

As the place of National and Cultural Concepts according to writing type and themes in primary school first grade, second term reading and writing textbook are given in the order of their frequency; historical figures (45), family (28) and elders (28), human relations (22), national holidays (15), homeland (15), places (10), flag (9), national anthem (6), yurt (5), nation (5), our cities (4), Turkish (2), historical works (1). It has been seen that religious holidays, traditions, traditional sports, Turkish, foundation culture and silence, immigration are not included in the first grade, second term43reading and writing textbook. However, in the second term of the first reading and writing textbook, it was seen that more concepts were included in the first term textbook, and it was found that there were 194 national and cultural concepts in total. 
When the status of National and Cultural Concepts according to writing type and themes in primary school second grade reading and writing textbook are given in the order of frequency;

human relations (109), family (98), our cities (64), historical figures (50), places (36), flag (17), historical works (12), our spells (8), Turkish (8), Turkish National Anthem (7), Anatolia (5), dormitory (5), homeland (4), religious holidays (4), traditions (3), national holidays (3), traditional sports (2), Turkish (2), migration (2) and Foundation Culture and homesickness are not included in the second grade Turkish textbook of primary school. In total, the number of national and cultural concepts in the primary school, second grade Turkish textbook were found to be 439. According to this finding, it can be said that national and cultural concepts are given a higher place in the second grade when compared with the first grade primary reading and writing textbook.

\section{Conclusion Discussion and Suggestions}

As a result of the examination; some of the national-cultural concepts have not been found sufficiently presented in the first and second grade Turkish textbooks of primary school and some of them are not included at all. Besides, some national and cultural concepts were presented more intensely in some themes and some were less.

In the study of Yilar (2016), it was found out that the concepts of human relations were the most presented concepts in the Turkish textbook of primary school, so when textbooks were being created, some concepts were given less space than they should be given (Years, 2016: 502). Besides, the most emphasized value concepts in the textbooks are love, helpfulness, patriotism, sharing and respect (Kaşkaya \& Duran, 2017), and there are some similar concepts in other researches (Kumbasar, 2011; Şahin, 2010).

When looked at the common points of all the sub questions; the concept of family, which is a national and cultural concept, is included in common high frequencies in all three books, and the concept of Foundation Culture and foundation/ migration is not included in all three books; the place of national and cultural concepts in second-grade Primary School Turkish textbooks is (439) more than the first grades of primary school in reading and writing textbooks which were $(45,194)$.

Based on the results of the study; 
1. A more balanced review of the distribution of national and cultural concepts in the first and second grade level Turkish textbooks can be done,

2. Consistent re-distribution of national and cultural concepts can be done to texts that were given less or no space,

3. Preventing certain concepts from taking place in some themes and in some not, can be done,

4. Examination of the place of national and cultural concepts in different grade-level textbooks published by different publishers can be done.

5. Consideration of different dimensions of national and cultural concepts according to the number of themes and types, can be examined.

6. National and cultural concepts should be examined by considering the concepts suggested under different themes. 